\title{
The optimal composition of reagents for producing aluminosilicate glue based on fly ash of thermal power plants
}

\author{
Elena Yu. Temnikova ${ }^{1, *}$, Alexey A. Lapin ${ }^{1}$, and Alexander R. Bogomolov ${ }^{1,2}$ \\ ${ }^{1}$ T.F. Gorbachev Kuzbass State Technical University, Department of Heat Power Engineering, \\ 650000 Kemerovo, 28 Vesennya st., Russian Federation \\ ${ }^{2}$ Kutateladze Institute of Thermophysics SB RAS, 630090 Novosibirsk, 1 Ak. Lavrent'eva ave., \\ Russian Federation
}

\begin{abstract}
The work is devoted to the processing of fly ash wastes obtained from coal combustion. Based on the non-magnetic fraction of fly ash (its particle size of $0-50 \mu \mathrm{m}$ ), an aluminosilicate glue or liquid glass as a cementing component has been obtained. It was represented by a number of silicate modules $\left(\mathrm{SiO}_{2} / \mathrm{Me}_{2} \mathrm{O}\right.$ molar ratios): $2,2.5$ and 3 (for three different formulations). The shear deformation tests for glued plates with glues of various silicate modules have been carried out. The shear stresses for the samples with silicate modules of 2.0, 2.5, 3.0 were equal to 48,66 and $34 \mathrm{kPa}$, respectively. These results suggest that during the production of aluminosilicate glue, the silicate module of 2.5 is more favored for providing the strongest bond between ceramic tiles.
\end{abstract}

\section{Introduction}

Liquid glass-based acid-resistant building materials are widely used in construction as silicate polymer concrete, putty, etc. In particular, soluble sodium silicates (liquid glasses) are often employed as binding components for the production of heat-resistant and chemically resistant materials. Liquid glasses are light and safe. They also have high cohesive strength. Besides that, they have low cost, do not corrode, do not evaporate firehazardous volatile components and, hence, do not harm the environment during operation.

The main method for industrial production of liquid glass is the production of alkalisilicate solid glasses (silicate-clumps) and their autoclave dissolution in water by hydrothermal or solvothermal synthesis [1]. In this case, the silicate module of the generated sodium liquid glass has a range of values from 2 to 3.5 [1].

There are also other methods for producing liquid glasses including one-pot direct dissolution of silica-containing components in caustic alkalis to obtain the required alkalisilicate solutions (liquid glasses) using a single reactor process. The method described in [1] did not attract significant attention in industry, mainly due to the instability of the technological process, caused by the wide variability in the composition and properties of raw silica-containing materials, high values of dissolution parameters (temperature and

*Corresponding author: teu.pmahp@kuzstu.ru 
pressure), worse quality of the product (compared to silicate-clump production), larger amounts of industrial wastes, a deficiency of caustic alkali and the complexity of obtaining high-modulus glasses. This method can be promising and more widely available in terms of producing liquid glass as a by-product of the main production or as one of the products of complex processing of mineral raw materials.

A non-magnetic part of fly ash generated after the separation of microspheres and magnetic fraction from the ash can be served as valuable mineral feedstock for the production of liquid glass. It is known that the nonmagnetic part of fly ash contains from 45 to $60 \%$ of silicon oxides $\left(\mathrm{SiO}_{2}\right)$ and from 15 to $20 \%$ of aluminum oxides $\left(\mathrm{Al}_{2} \mathrm{O}_{3}\right)$ [2]. According to the chemical and granulometric compositions, fly ash (the representative fraction of which has a particle size of $0-50 \mu \mathrm{m}$ ) is largely identical to natural mineral raw materials used for the production of various building materials and inorganic binders [2-3]. In addition, ash contains calcium oxide [2], which can act as reagents for curing.

Fly ashes formed in Kuzbass thermal power stations are, in fact, the low-calcium or acidic ashes $(\mathrm{CaO}$ content $<10 \%)$. It is believed that only the glass phase in low-calcium fly ash can react with alkalis or lime (free $\mathrm{CaO}$ ); therefore, such materials should be considered as inert pozzolanic (pulverulent) fillers (class $\mathrm{F}$ - low-calcium pozzolan of acidic nature, due to high content of $\mathrm{SiO}_{2}-\mathrm{Al}_{2} \mathrm{O}_{3}$ ), but not hydraulically active basic materials (class C - high-calcium ash) [3-5].

Since crystalline minerals in low-calcium fly ash do not possess high reactivity at ordinary hydration temperatures, the binding properties of such ash generally deteriorate with increasing the concentration of these minerals relative to the content of non-crystalline (vitreous) components. Researchers point to an analogy between the production of silicate glue and the astringent properties of fly ash. The pozzolanic activity of materials rises with increasing the fineness of its grinding, as well as with adding of alkalis [6].

Hydraulically active minerals in fly ashes are often either inside the droplets of the vitreous phases or covered with glass, which makes it difficult for the minerals to come in contact with water. Therefore, when fly ash is used for obtaining binders, it is necessary to destroy the glass phases in order to release the active components, i.e., a preliminary stage of fly ash grinding (or its treatment with suitable chemical reagents) is required [4].

In this connection, the authors suggest that for the production of silicate glue (more precisely, aluminosilicate adhesive, since the amount of aluminum oxide in this case is rather significant), it is reasonable to use a fraction of fly ash particles sizing from 0 to 50 $\mu \mathrm{m}$. Such ash does not require additional grinding, and it has a sufficient amount calcium oxide in its composition.

The purpose of the work is to obtain a cement component based on aluminosilicate glue with the optimal composition of the reagents from fly ash of thermal power stations.

\section{Methods and experimental results}

Fly ash granulometric composition studies carried out by the authors show that at the coalbased thermal stations with wet dust collection, the fraction of fly ash particles of $0-50 \mu \mathrm{m}$ in size reaches $76-78 \%$ (by weight). With dry dust collection in electrostatic precipitators, the amount of fly ash of the same class size is of 53-66\%. The use of such a fraction is of interest in the production of aluminosilicate adhesive, since the main elements and oxides contained in the fly ash are silica and alumina. In this work, fly ash after separation of magnetite $\left(\mathrm{Fe}_{3} \mathrm{O}_{4}\right)$ and hematite $\left(\mathrm{Fe}_{2} \mathrm{O}_{3}\right)$ was subjected to sifting into three representative fractions: $0-50 ; 50-80$; and $80-1000 \mu \mathrm{m}$. Analysis shows that with the increase in ash particle sizes, the amount of acidic oxides $\left(\mathrm{Al}_{2} \mathrm{O}_{3}\right.$ and $\left.\mathrm{SiO}_{2}\right)$, as well as basic oxides $\left(\mathrm{Fe}_{2} \mathrm{O}_{3}\right.$, $\mathrm{MgO}, \mathrm{Na}_{2} \mathrm{O}, \mathrm{K}_{2} \mathrm{O}$ ), except $\mathrm{CaO}$, tends to decrease. The elemental and oxidic compositions of the non-magnetic part of fly ash particles of $0-50 \mu \mathrm{m}$ in size are presented in Table 1 . 
Element and oxid content was determined using the scanning electron microscopy method using the scanning electron microscope JEOL JSM-6390 LA with the energy-dispersive Xray detector JED 2300 of the Collective Use Center of the Federal Research Center for Coal and Coal Chemistry, RAS.

Table 1. The elemental and oxidic compositions of the non-magnetic part of fly ash particles of $0-50 \mu \mathrm{m}$.

\begin{tabular}{|c|c|c|c|c|c|c|c|c|c|c|c|c|}
\hline $\begin{array}{c}\text { Element/ } \\
\text { Compound }\end{array}$ & $\mathrm{C}$ & $\mathrm{O}$ & $\begin{array}{c}\mathrm{Na} / \\
\mathrm{Na}_{2} \mathrm{O}\end{array}$ & $\begin{array}{c}\mathrm{Mg} / \\
\mathrm{MgO}\end{array}$ & $\begin{array}{c}\mathrm{Al} / \\
\mathrm{Al}_{2} \mathrm{O}_{3}\end{array}$ & $\begin{array}{c}\mathrm{Si} / \\
\mathrm{SiO}_{2}\end{array}$ & $\begin{array}{c}\mathrm{P} / \\
\mathrm{P}_{2} \mathrm{O}_{5}\end{array}$ & $\begin{array}{c}\mathrm{S} / \\
\mathrm{SO}_{3}\end{array}$ & $\begin{array}{c}\mathrm{K} / \\
\mathrm{K}_{2} \mathrm{O}\end{array}$ & $\begin{array}{c}\mathrm{Ca} / \\
\mathrm{CaO}\end{array}$ & $\begin{array}{c}\mathrm{Ti} / \\
\mathrm{TiO}_{2}\end{array}$ & $\begin{array}{c}\mathrm{Fe} / \\
\mathrm{Fe}_{2} \mathrm{O}_{3}\end{array}$ \\
\hline $\begin{array}{c}\text { Concentration, } \\
\% \text { (Wt.) }\end{array}$ & $\begin{array}{c}20,77 / \\
20,77\end{array}$ & $\begin{array}{c}36,64 / \\
0,00\end{array}$ & $\begin{array}{c}1,03 / \\
1,39\end{array}$ & $\begin{array}{c}1,19 / \\
1,98\end{array}$ & $\begin{array}{c}8,22 / 1 \\
5,53\end{array}$ & $\begin{array}{c}20,13 / \\
43,06\end{array}$ & $\begin{array}{c}0,21 / \\
0,49\end{array}$ & $\begin{array}{c}0,34 / \\
0,85\end{array}$ & $\begin{array}{c}1,81 / \\
2,18\end{array}$ & $\begin{array}{c}5,35 / \\
7,49\end{array}$ & $\begin{array}{c}0,49 / \\
0,82\end{array}$ & $\begin{array}{c}3,80 / \\
5,43\end{array}$ \\
\hline
\end{tabular}

It should be noted a greater specific surface area $\left(\mathrm{m}^{2} / \mathrm{kg}\right)$ of a granulometric layer of highly dispersed fly ash for interaction of the introduced reagent (e.g., caustic) with the surface of microspheres. Thus, for a cubic packing of a granulometric layer, the specific surface area of fly ash can be calculated as: $S_{u d}=6 /(d \rho)$, where $\mathrm{d}$ is average (median) diameter of fly ash particles, $\mathrm{m}$; $\rho$ is density of ash particles, $\mathrm{kg} / \mathrm{m} 3$.

A schematic diagram of an apparatus for manufacturing (cooking) liquid glass under laboratory conditions is depicted in Fig. 1. The unit is placed in a fume hood (not shown in Figure 1) for removing the vapors having formed.

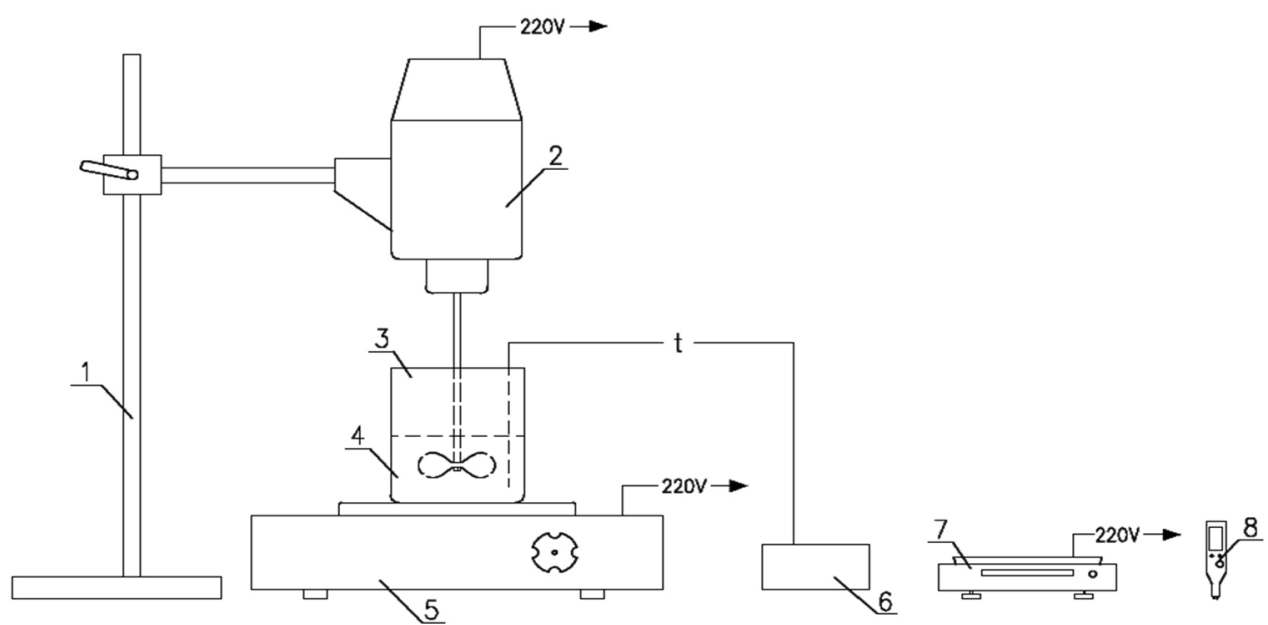

Fig. 1. Scheme of a setup for producing liquid glass: 1 is tripod with a clamp; 2 is agitator with electric motor; 3 is metallic vessel; 4 is suspension; 5 is electric stove with a heating regulator; 6 is measuring instrument (an OWEN temperature regulator); 7 is electronic scales; 8 is $\mathrm{pH}$ meter.

To prepare the suspension, a non-magnetic fraction of fly ash with particle sizes of 0-50 $\mu \mathrm{m}$, being mixed with a $43 \%$ aqueous solution of sodium hydroxide $(\mathrm{NaOH})$ and an appropriate amount of water have been used as the raw materials.

When preparing liquid glass, the order of operations at the setup (Fig. 1) as follows. With using electronic scales 7 , the certain amounts of weighed mixed components are prepared, which are loaded into the vessel 3. This results in the formation of a suspension 4. Then, the liquid glass is produced from the suspension 4 in a metallic vessel 3 installed on the electric stove 5 . The given process is conducted with constant stirring provided by an electric mixer 2 fixed with a clamp on a tripod 1 . The suspension temperature is monitored by an OWEN measuring instrument 6 . For controlling the acidity of liquid glass being 
produced, a pH meter 8 is used. The duration of the process is determined by a stopwatch (not indicated in the Fig. 1).

Under the laboratory conditions, an aluminosilicate adhesive (gel) or liquid glass as a cementing component for binding (bonding) of two surfaces of the inorganic substrate has been obtained by the authors in KuzSTU. The adhesive was represented by a number of silicate modules $(2 ; 2.5$ and 3$)$ for three different formulations and was prepared according to the following technology. The following components were mixed: a non-magnetic part of fly ash with particle sizes of 0-50 $\mu \mathrm{m}$ (comprising $60 \mathrm{~g}$ of $\mathrm{SiO}_{2}$ ) - $72 \mathrm{~g}+\mathrm{NaOH}(\mathrm{a} 43 \%$ aqueous solution) $-62.0 \mathrm{~g}+\mathrm{H}_{2} \mathrm{O}-88.0 \mathrm{~g}$ (an adhesive with a silicate module 3 as a typical example).The mixture was heated to $80-90^{\circ} \mathrm{C}$ and stirring for $50-60$ minutes at this temperature with controlling the process so that the temperature did not exceed $90^{\circ} \mathrm{C}$. At this temperature, the smallest $\mathrm{SiO} 2$ particles begin to dissolve in the $\mathrm{NaOH}$ solution, which is accompanied by a spontaneous temperature increase. The temperature regime $\left(80-90^{\circ} \mathrm{C}\right)$ is kept until a thin film appears on the surface of the suspension; after that the product acquires a brilliant oily appearance with a constant viscosity throughout the volume. The aluminosilicate glue is then cooled under ambient conditions. As a result, aluminosilicate glue in the form of a dense bulk was obtained, covered with a shiny film (crust) on top.

At alkali concentrations below $5 \mathrm{M} \mathrm{NaOH}$ (i.e., under the conditions of our experiments), the main product of mullite ${ }^{\dagger}$ transformations is zeolite [7]. A study of the temperature dependence for the reaction of fly ash with a $4 \mathrm{M} \mathrm{NaOH}$ aqueous solution showed [7] that with increasing the reaction temperature from 75 to $160^{\circ} \mathrm{C}$, the processes of progressive formation of $\mathrm{Na}$-containing zeolite-like structures take place. Therefore, in order to obtain the zeolite $\mathrm{P}$, a reaction temperature within $80-95^{\circ} \mathrm{C}$ was kept during the formation of the aluminosilicate adhesive.

After cooling the liquid glass, a process of gluing ceramic tiles was conducted. The results of the shear strain tests for platelets glued with gels (glues) having various silicate modules were as follows: tangential stresses for shearing two faience plumbing plates glued with glues having silicate modules of 2.0, 2.5 and 3.0 were equal to 48,66 and $34 \mathrm{kPa}$, respectively. The results obtained point to the need for keeping the silicate module of 2.5 in the production of aluminosilicate glue to obtain the strongest bond between ceramic tiles.

\section{Conclusion}

The results of experimental studies on aluminosilicate glue production indicate that the optimal composition of reagents for its preparation must have a silicate module of 2.5 , with fly ash grain sizes varying in the range of 0-50 $\mu \mathrm{m}$. Such formulation does not require additional grinding and makes it possible to obtain the strongest bond between ceramic tiles (up to $66 \mathrm{kPa}$ )

\section{References}

1. V.I. Korneyev, V.V. Danolov, Liquid and soluble glass (1996)

2. A.S. Sysolyatin, I.A. Zvingul, K.Yu. Ushakov, L.Yu. Belyaevskaya, E.Yu. Temnikova, Collection of the best articles of the VIII All-Russian Scientific and Practical Conference of Young Scientists "Russia Young" (2016)

3. M. Thomas, R. Jewell, R. Jones, Coal Combustion Products (CCP's). Characteristics, Utilization and Beneficiation (T. Robl, A. Oberlink and R. Jones, Eds.) (2017)

\footnotetext{
${ }^{\dagger}$ Mullite (Al6Si2O13) is practically the only crystalline phase present in low-calcium fly ashes used in this work.
} 
4. M.A. Savinkina, A.T. Logvinenko, Ashes of Kansk-Achinsk brown coals (1979)

5. V.V. Zyryanov, D.V Zyryanov, Fly ash - raw materials (2009)

6. L.I. Dvorkin, O.L. Dvorkin, Construction mineral binder materials (2011)

7. Zh. Jiang, J. Yang, H. Ma, L. Wang, X. Ma, Trans. Nonferrous Metals Soc. 25, 6 (2015) 